\title{
ESTUDO PRELIMINAR SOBRE AS OCORRENCIAS DE TURFA NO VALE DO RIBEIRA DE IGUAPE, SP.
}

\author{
Theodoro KNECHT *
}

\begin{abstract}
RESUMO
As pesquisas de turfa e argila no vale do Rio Ribeira de Iguape, SP, realizadas por volta de 1973-74, são aqui mencionadas e divulgadas, em vista do grande interesse da turfa, no momento, como nova fonte energética.

São descritas várias ocorrências e executadas inúmeras sondagens a trado, em uma área de várzea de $6.640 .000 \mathrm{~m}^{2}$ que acusaram uma reserva de $20.904 .000 \mathrm{~m}^{3}$ de turfa úmida e $3.600 .000 \mathrm{~m}^{3}$ de argila, em grande parte aproveitável para indústria cerâmica.
\end{abstract}

\begin{abstract}
, The researches about turf and clay in the Rio Ribeira de Iguape valley, realized around 1973-74, are published now, due the great interest in turf, in the moment, as a new source of energy.

It is described many occurrence and performed innumerable boreholes in a led area of $6.640 .000 \mathrm{~m}^{2}$ which showed a store of $20.904 .000 \mathrm{~m}^{3}$ concerning moist turf and $3.600 .000 \mathrm{~m}^{3}$ concerning clay, almost totality profitable to pottery industry.
\end{abstract}

\section{APRESENTAÇÃO}

Durante os anos de 1973 e 1974 o Engenheiro Theodoro Knecht realizou para o Instituto Geográfico e Geológico, pesquisas minerais no vale do Rio Ribeira de Iguape, com ênfase para as argilas e turfa.

Devido à preocupação das diversas comunidades pela escassez, a médio prazo, dos recursos energéticos convencionais, a procura de novas fontes faz-se premente no momento atual.

No Brasil são conhecidas desde 1930 , as turfeiras do vale do Rio Paraíba do Sul que tiveram seus estudos intensificados com aproveitamento pela antiga Estrada de Ferro Central do Brasil, no período da II Grande Guerra, sendo que a partir de 1945, "não há registro de produção significativa de turfa para qualquer fim" (SHIMADA \& CARVALHO, 1980).

Esses autores (op. cit) afirmaram que "no Brasil e no Estado de São Paulo, em particular, esse aproveitamento encontra-se ainda no campo das perspectivas, uma vez que o assunto continua carente de um estudo abrangente começando por um completo levantamento e caracterização das turfeiras existentes".

Um retrospecto histórico da utilização da turfa no Estado de São Paulo foi apresentado por SHIMADA \& CARVALHO (op. cit), salientando o abandono das pesquisas, com exceção de Theodoro Knecht que enfatizou, em seu trabalho, publicado em 1955-58, a importância de turfa na produção de energia, obtenção de subprodutos como nitrogênio, óleo, parafina, álcool e como fertilizante de solo, sob forma de turfa bacterizada em mistura com calcário moído.

O Engenheiro Theodoro Knecht mencionou, nesse trabalho, a ocorrência de turfeiras ao longo do curso superior do Rio Tietê e seus afluentes, em Mogi das Cruzes, Suzano, Mococa, São Vicente, Peruíbe, Itapeva, Iguape e Registro, estimando as reservas do Estado, sem exageros, em dezenas de milhões de toneladas.

Engenheiro aposentado - Instituto Geológico - Caixa Postal 8772 - 01000 São Paulo, Brasil. 
Em 1965, MEZZALIRA, também em seus trabalhos de levantamentos geológicos para as folhas de Piracicaba e São Carlos, assinalou a ocorrência de sedimentos turfosos nos vales dos ribeirões do Lobo e Itaqueri e nos arredores de Campo Alegre, Itirapina e Visconde de Rio Claro.

Assim, durante a nossa gestão na Diretoria do Instituto Geológico no decorrer de 1981, devido ao interesse demonstrado por alguns pesquisadores em conhecer o resultado dessas pesquisas sobre turfeiras feitas pelo Instituto Geológico, através do Engenheiro Theodoro Knecht, na região do vale do Ribeira, resolvemos divulgar aquelas pesquisas objetivando contribuir, embora em pequena escala, para o conhecimento, avaliação e possível aproveitamento de outras fontes energéticas, nos mais variados

\section{INTRODUÇÃO}

As ocorrências de turfa e argila encontram-se restritas às várzeas dos rios $\mathrm{Ja}$ cupiranga, Boa Vista, Registro, Vermelho, Carapiranga, Bamburral e outros (veja planta anexa). A turfa existente nas várzeas desses ribeirões, contém em média $85 \%$ de água. Os depósitos de turfa diferem uns dos outros não só devido à flora que lhes dá origem, como também pelo processo de decomposição sob a água. Portanto, o valor da turfa, nas áreas estudadas, é variável de uma várzea para outra e, às vezes, na mesma área.

A turfa e a argila, em geral sotoposta, ocorrem, de preferência, nas várzeas do curso inferior dos afluentes já mencionados do Rio Ribeira e sujeitas à freqüentes inundações periódicas Mesmo em tempo de seca, apresentam-se úmidas e pantanosas, cobertas por águas estagnadas. A altitude das turfeiras pesquisadas no curso inferior dos afluentes encontra-se entre 5 e $7 \mathrm{~m}$ acima do nível do mar e, aproximadamente, entre 2 e $3 \mathrm{~m}$ sobre o nível do Rio Ribeira. Nos cursos, médio e superior dos afluentes, a altitude das várzeas varia entre 8 e $13 \mathrm{~m}$ sobre o nível do mar. As várzeas ao longo dos afluentes acham-se, via de regra, orientadas em direção NNE-SSW ou, aproximadamente. A densidade da turfa, co- campos agro-industriais, devido à versatilidade da turfa que se "reveste da maior importância, uma vez que a viabilidade econômica do seu aproveitamento energético pode ser altamente melhorada ao se considerar a utilização industrial e sub-produtos" (SHIMADA \& CARVALHO, op. cit.)

A pesquisa não chegou a ser completada com as análises necessárias para determinações físicas e físico-químicas das turfeiras para avaliar as suas possibilidades energéticas, contudo a apresentação do trabalho vem demonstrar as dificuldades encontradas no desenvolvimento das pesquisas e as reservas de turfa existentes naquela região paulista.

\section{Dr. Sergio Mezzalira \\ Ex-Diretor Geral do Instituto Geológico}

lhida por meio de sondagem manual, é de 0,8 . As várzeas estão sujeitas a inundações sendo, em grande parte, cobertas com meio metro de água ou mais, o que torna penosa ou às vêzes impossível a execução dessas sondagens. Pelas análises executadas verificou-se que a umidade a $100^{\circ} \mathrm{C}$ é da ordem de $15 \%$.

Verificou-se também que a turfa colhida nos furos e uma vêz sêca, não se torna higroscópica. Ao nosso ver as turfas das várzeas estudadas podem ser utilizadas para a produção de gás, alcatrão, condicionador de solos, carga e diluente para adubos químicos, etc. O problema capital da aplicação da turfa é que a secagem mais recomendada é a natural, que é muito lenta e dependente das condições atmosféricas. E lícito dizer que o problema da distilação de certos tipos de turfa para obtenção de óleo mineral tem sido aventado desde muito anos, não se podendo considerá-lo, porém, de solução econômica em tempos normais, como sucedâneo dos combustíveis líquidos naturais.

SETZER apud, FROES ABREU, (1973), sugere o aproveitamento da turfa no Brasil para o fornecimento de matéria orgânica ao solo. Seu emprego como carga 
e diluente para adubos químicos é também mais recomendável do que como fonte de energia

Consideramos que há várzeas bem desenvolvidas em parte devido a fenôme- nos tectônicos, o que não é cabível aqui explicar, já que o objetivo principal consistia na pesquisa de argilas e turfas para fins industriais.

\section{METODOLOGIA}

As pesquisas geológicas de superfície e subsuperfície das turfeiras obedeceram, dentro das possibilidades, ao seguinte programa:

1. Colheita de amostras de turfa e argila até a profundidade de 5 metros.

2. Avaliação da espessura máxima.

3. Verificação do contorno e conteúdo das várzeas onde existem turfa e argila.

4. Estudo do embasamento da turfeira e da argila.

5. Constituição das turfeiras e do depósito da argila.

6. Relação entre a vegetação (piriguaçu, taboa, capim seco, macega e arbustos) e a qualidade da turfa.

Análises de amostras de turfas, colhidas em anos anteriores, acusaram os seguintes teores:

\begin{tabular}{cccr}
1 & 2 & 3 & \multicolumn{1}{c}{4} \\
47,7 & 36,0 & 42,7 & 42,5 \\
16,87 & 13,4 & 29,7 & 9,1 \\
23,55 & 18,3 & 24,5 & 15,0 \\
11,84 & 32,1 & 3,1 & 33,4
\end{tabular}

Poder calorífico da turfa seca: ....... 2.439,2 cal.

Localidades: 1. Várzea do Rio Guaraú;

2. Várzea do Rio Juquiá;

3. Várzea da Fazenda São João, perto de Peruíbe;

4. Várzea do Rio Quilombo, Município de Sete Barras.

\section{MATERIAL}

3.1 - Turfeira da várzea do Ribeirão Registro

As sondagens executadas na várzea do Ribeirão Registro, em número de 26 , revelaram um importante depósito de turfa de boa qualidade e as feitas ao longo deste Ribeirão permitem delimitar uma área de aproximadamente $1.200 .000 \mathrm{~m}^{2}$. Para a cubagem mais segura adotamos uma espessura média de $3 \mathrm{~m}$.
As análises de duas amostras médias de turfa obtida na várzea do Ribeirão Registro acusaram, segundo o Laboratório de Química do Instituto Geográfico e Geológico, os seguintes resultados:

$$
\begin{array}{cc}
\text { Análise } & \text { Análise } \\
\text { n. } .^{\circ} 13.421 & \text { n. }{ }^{\circ} 13.510
\end{array}
$$

Cinza. . . . . $\quad 11,5 \% \quad 33,7 \%$ Matéria volátil. . $\quad 51,4 \% \quad 32,6 \%$ Carbono fixo. . . $25,3 \% \quad 16,9 \%$ Umidade . . . . $11,8 \% \quad 16,8 \%$ 
A turfeira do Ribeirão Registro possui, ao longo deste Ribeirão, um comprimento de cêrca de $3 \mathrm{~km}$ e uma largura de $400 \mathrm{~m}$ e sobrepõe-se a uma argila plástica de cor cinzenta, encontrada nas cabeceiras deste Ribeirão. Localmente é arenosa e manchada de hidróxido de ferro. Diversos furos, executados com grande dificuldade devido à lamina de água sobre a turfeira, apresentaram espessuras entre 2 e $5 \mathrm{~m}$ de camada de turfa. As suas reservas podem ser avaliadas, aproximadamente, em $3.600 .000 \mathrm{~m}^{3}$, com um teor de $70 \%$ de água, adotando-se a espessura média de $3 \mathrm{~m}$. A vegetação que cobre a área responsável pela formação da turfa, consiste de taboa, piriguaçu, capim seco e outras plantas.

\section{2 - Turfeira da várzea do Ribeirão Boa Vista}

Volumosas reservas de turfa que se sobrepõem à argila cinzenta plástica, com espessura de $0,80 \mathrm{~m}$, em média, foram assinaladas na várzea do curso inferior do Ribeirão Boa Vista. Foram executadas 24 sondagens em diversas várzeas ao lado da nova rodovia Registro-Sete Barras.

A partir da barra deste Ribeirão com o Rio Ribeira, a camada de turfa, em altitudes entre 2 a $9 \mathrm{~m}$, ocupa uma área de aproximadamente $2 \mathrm{~km}$ de comprimento e $200 \mathrm{~m}$ de largura, em média. A turfa desta várzea é, como aliás em todas as várzeas pesquisadas, proveniente da carbonização não somente do piriguaçu, como também da vegetação de taboas, lírios e plantas rasteiras, tais como o capim sêco. Em alguns outros pontos desta várzea a vegetação responsável pela formação da turfa é a taboa.

A turfa deste Ribeirão apresenta-se com elevado teor em água, entre 70 a $80 \%$, pouca coesão, cor parda escura ou preta e composta de restos dos vegetais superiores acima mencionados.

A argila de cor cinzenta sotoposta à camada de turfa, possui alta plasticidade e apresenta-se sem areia perceptível. Não conseguimos penetrar na várzea das cabeceiras deste Ribeirão, visto que a mesma acha-se alagada até $50 \mathrm{~cm}$ sobre a turfa. No curso inferior do Ribeirão Boa Vista, podemos admitir, de acordo com os resultados obtidos pelas perfurações, uma espessura média de $0,80 \mathrm{~m}$ de turfa em parte sapropelítica e $1,50 \mathrm{~m}$ de argila sotoposta à mesma. Segundo Sylvio Fróes Abreu, temos no Brasil turfas de dois tipos: as turfas de gramíneas, ciperáceas e outras plantas que crescem nos pântanos, bem como as turfas de algas ou sapropelitos, que têm $o$ aspecto de uma lama com poucos detritos de plantas superiores. Não encontramos na região, turfa - sapropelito conforme conceito acima de FRÓES ABREU (1973).

A reserva de turfa, somente no curso inferior deste Ribeirão, é da ordem de $320.000 \mathrm{~m}^{3}$ e a de argila, de $600.000 \mathrm{~m}^{3}$.

A análise de uma amostra média da turfa desta várzea, feita no Laboratório de Química do Instituto Geográfico e Geológico, acusou os seguintes resultados:

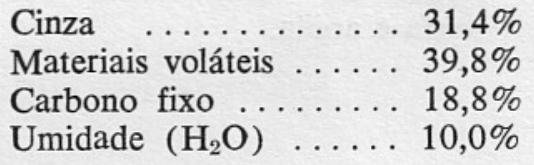

3.3 - Turfa da várzea do Rio Bamburral

A turfeira da várzea do Rio Bamburral, afluente da margem esquerda do Rio Jacupiranga, faz parte de extenso brejão ao sul do Rio Ribeira. Neste brejão ocorrem, segundo nossos estudos, os maiores depósitos de argila e turfa verificados até o fim do ano de 1974.

A área estudada na várzea do Rio Bamburral, por sondagens em número de 26 e que atingiram profundidades entre 2 e $6 \mathrm{~m}$, é de $3.000 .000 \mathrm{~m}^{2}$, sendo a espessura média da turfa de $2,00 \mathrm{~m}$. Prevê-se que a área ainda a ser pesquisada e que apresenta indícios de turfa entre os rios Jacupiranga, Bamburral e Ribeira de Iguape é de aproximadamente $18 \mathrm{~km}^{2}$.

As elevações que atingem, ao norte do curso do Rio Bamburral, altitudes entre 35 e $45 \mathrm{~m}$, são constituídas pelo embasamento cristalino profundamente decomposto, que se acha sotoposto, em parte, ao cascalho (terraço fluvial), até o nível do rio. $\mathrm{Na}$ região ao sul do Rio Jacupiranga, as elevações também constituídas de rochas cristalinas (gnaisse e migmatito decompos- 
to) são menos pronunciadas e as altitudes variam entre 25 e $30 \mathrm{~m}$.

As altitudes da várzea variam entre 5 e $7 \mathrm{~m}$ sobre o nível do mar. A vegetação que cresce sobre a turfeira consiste em parte de bosques de lignoniáceas (caxetas), achando-se atualmente, em exploração. Localmente a área da várzea é ocupada por vegetação herbácea, como taboa, lírio, piriguaçu, capim seco, etc.

A vegetação desta várzea difere bastante daquela das colinas que a circundam entre os rios Bamburral, ao norte, e Jacupiranga, ao sul, como também da vegetação sobre dunas e restingas antigas perto da costa.

A área em apreço apresenta-se em média com uma largura de mais de um $\mathrm{km}$ e acha-se orientada na direção E-W, segundo o curso médio do Rio Bamburral. No seu curso superior, perto da fábrica de chá, estreita-se para $300 \mathrm{~m}$. A área adjacente ao Rio Bamburral, para o lado do Rio Ribeira encontra-se alagada, tornando-se penosa a penetração para execução de sondagens, devido à cobertura de água, que chegou até $50 \mathrm{~cm}$ sobre a superfície da turfeira. Localmente a turfa acha-se mais ou menos consolidada e em outros lugares aparece argila altamente plástica de cor cinzenta, sotoposta a terra vegetal de espessura de $0,30 \mathrm{~m}$.

A qualidade e a quantidade da turfa dependem da natureza da vegetação piriguaçu. Concordamos com a opinião de SILVEIRA (1952) de que as dunas e restingas antigas dificultam o escoamento das águas fluviais e determinam a formação de zonas alagadas em todos os afluentes do Rio Ribeira.

As sondagens executadas no curso superior do rio em apreço e perto do caminho que atravessa a várzea, mostraram uma espessura de $4 \mathrm{~m}$ de turfa e não atingiram a argila ou o embasamento cristalino.

3.4 - Turfa, em parte sapropelítica e argila, nos cursos, inferior e médio do Ribeirão Vermelho, junto à sua barra com o Rio Ribeira.

Em extensa área, situada no curso inferior do Ribeirão Vermelho, verificou-se que a turfa de boa qualidade ocorre em duas camadas separadas por uma outra estéril de argila.

As pesquisas por sondagens nesta extensa várzea do curso inferior do Ribeirão, não foram terminadas. A sua área pesquisada é de aproximadamente $600.000 \mathrm{~m}^{2}$. Junto à barra do Ribeirão Vermelho, a camada de argila cinzenta clara e altamente plástica possui uma espessura de $1,20 \mathrm{~m}$ e acha-se sotoposta por uma camada de turfa de 2,20 m e sobreposta por turfa mais sapropelítica de $0,50 \mathrm{~m}$ de espessura, em média. Abaixo desta profundidade, a argila apresenta-se mais arenosa e manchada de hidróxido de ferro. A reserva de turfa verificada, atinge cerca de $1.320 .000 \mathrm{~m}^{3}$ e a de argila, aproximadamente $720.000 \mathrm{~m}^{3}$.

A análise n. ${ }^{\circ} 13.509$ do IGG - Turfa sapropelítica do curso inferior do Ribeirão Vermelho, acusou:

$\begin{array}{lll}\mathrm{H}_{2} \mathrm{O} \ldots \ldots \ldots \ldots & 16,8 \% \\ \text { Carbono fixo } \ldots \ldots \ldots & 16,9 \% \\ \text { Matéria volátil } \ldots \ldots & 32,6 \% \\ \text { Cinza } \ldots \ldots \ldots \ldots \ldots & 33,7 \%\end{array}$

No curso médio deste Ribeirão, a turfa encontrada acusou a seguinte composição:

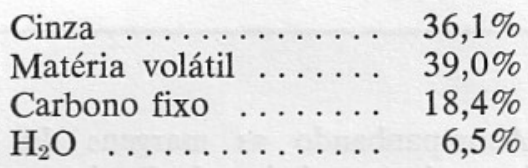

3.5 - Argila e turfa nas obras do dique "Polder", na margem esquerda do Rio Ribeira de Iguape.

Foram realizados estudos ao longo dos diques "Polder I e II", sob ponto de vista de aproveitamento de argila para indústrias de cerâmica. Ambos os diques acham-se situados na várzea seca da margem esquerda do Rio Ribeira. O dique "Polder I", que terá uma extensão de, aproximadamente, $10 \mathrm{~km}$, possui atualmente um comprimento de $7 \mathrm{~km}$ e $3 \mathrm{~m}$ de altura. Foi movimentado $1.000 .000 \mathrm{~m}^{3}$ de terra, abrangendo a rede de irrigação e drenagem, em uma área de 1.400 hectares, ou seja, 14 milhões de metros quadrados. A outra área possui 25 milhões de metros quadrados $(2.500 \mathrm{hec}-$ tares) e este segundo dique acha-se atualmente em construção situando-se pouco 
adiante do primeiro. A argila removida na construção do "Polder I" é de cor marron, cinza escura ou preta, bastante arenosa, possuindo quantidades variáveis de matéria orgânica e manchas de hidróxido de ferro. Apresenta regular plasticidade, sendo aplicável somente na indústria cerâmica vermelha, como na fabricação de tijolos e localmente é utilizada na fabricação de telhas em pequenas olarias, tanto na magem esquerda como na direita do Rio Ribeira.
Argila cinzenta plástica foi verficada perto do Porto Cabral e junto à ponte da rodovia onde se encontra o dique "Polder II", da segunda área em construção. Aqui existe, na valeta escavada para a construção do dique, ótima exposição de uma camada de argila cinzenta clara, altamente plástica, de possança de $2,00 \mathrm{~m}$. Acha-se sobreposta por uma camada de turfa com uma espessura de $0,40 \mathrm{~m}$.

\section{ANÁLISE DAS TURFEIRAS}

\begin{tabular}{lcccccc}
\hline & $\begin{array}{l}\text { RIBEIRÃO } \\
\text { REGISTRO }\end{array}$ & $\begin{array}{l}\text { RIBEIRÃO } \\
\text { BOA VISTA }\end{array}$ & $\begin{array}{l}\text { RIBEIRÃO } \\
\text { VERMELHO }\end{array}$ & & $\begin{array}{c}\text { DIQUE POLDER } \\
\text { GUAVIRUVA }\end{array}$ \\
\cline { 2 - 7 } & $\begin{array}{l}\text { Análise } \\
13.421\end{array}$ & $\begin{array}{c}\text { Análise } \\
13.510\end{array}$ & $\begin{array}{c}\text { curso inferior curso inferior } \\
\text { Análise } 13.509\end{array}$ & $\begin{array}{c}\text { médio } \\
13.511\end{array}$ & $\begin{array}{c}\text { Análise } \\
13.414\end{array}$ \\
\hline cinza & $11,5 \%$ & $33,7 \%$ & $31,4 \%$ & $33,7 \%$ & $36,1 \%$ & $38,6 \%$ \\
material volátil & $51,4 \%$ & $32,6 \%$ & $39,8 \%$ & $32,6 \%$ & $39,0 \%$ & $39,5 \%$ \\
carbono fixo & $25,3 \%$ & $16,9 \%$ & $18,8 \%$ & $16,9 \%$ & $18,4 \%$ & $15,6 \%$ \\
Umidade $\left(\mathrm{H}_{2} \mathrm{O}\right)$ & $11,8 \%$ & $16,8 \%$ & $10,0 \%$ & $16,8 \%$ & $6,5 \%$ & $6,3 \%$ \\
\hline
\end{tabular}

Acompanhando as margens do Rio Ribeira, acima e abaixo de Registro, verificou-se nestes trechos e em frente dos mesmos, na extensa valeta do dique "Polder I", que o material aluvionar do Rio Ribeira é constituído, até à profundidade de $4 \mathrm{~m}$, de argila preta ou amarela, em parte muito síltica e ferruginosa, aproveitável somente para cerâmica.

Esta argila passa gradualmente para turfa, à medida em que se acompanham as várzeas dos afluentes e se distancia do Rio Ribeira. Uma amostra de turfa colhida na valeta do dique "Polder" em construção perto de Jurumirim, possui a seguinte composição:

$$
\begin{array}{llr}
\text { Cinza } \ldots \ldots \ldots \ldots \ldots & 38,6 \% \\
\text { Matéria volátil } \ldots \ldots \ldots & 39,5 \% \\
\text { Carbono fixo } \ldots \ldots \ldots & 15,6 \% \\
\text { Umidade }\left(\mathrm{H}_{2} \mathrm{O}\right) & \ldots \ldots & 6,3 \%
\end{array}
$$

$\mathrm{Na}$ margem direita do Rio Ribeira, foram realizados numerosos furos junto à barra do Rio Carapiranga com o Rio Ribeira. Verificamos que a argila é de qualidade idêntica àquela exposta no dique "Polder I", na margem esquerda do Rio Ribeira, sendo a mesma aproveitável somente em cerâmica vermelha. O depósito desta argila, muito arenosa, acompanha somente a margem direita do Rio Ribeira, apresentando uma largura de aproximadamente 200 m. Para montante do Rio Carapiranga, a camada de argila passa abruptamente para turfa, em parte sapropelítica. Pelas sondagens executadas nesta várzea, que atingiram em média $4 \mathrm{~m}$, foi verificada uma reserva média de turfa de aproximadamente $9.600 .000 \mathrm{~m}^{3}$. A camada de argila arenosa e síltica extraída, nos barreiros, junto às pequenas olarias situadas na margem direita do Rio Ribeira possui, em média, espessura de $0,80 \mathrm{~m}$. 
3.6 - Descrição dos depósitos de argila e turfa - Região da Onça Parda e Ribeirão Fundo

Reservas vultosas de uma argila cinzenta plástica foram verificadas na várzea da margem direita do Ribeirão Fundo, afluente da margem direita do Rio Juquiá e merecem ser pesquisadas por sondagens.

O embasamento da várzea do Ribeirão Fundo é constituído por gnaisse fitado profundamente decomposto e como se observa nas exposições ao longo da rodovia Juquiá-Sete Barras, em construção, é atravessado por numerosas lentes de aplito caulinizado, deslocadas.

A camada de argila da várzea do Ribeirão Fundo possui espessura de 1,80 m, sendo sobreposta por turfa de possança de $1,20 \mathrm{~m}$. Os poucos furos feitos não permitem ainda uma cubagem da argila e da turfa. Porém, como estimativa, pode-se admitir que as reservas de ambas nesta várzea são vultosas, considerando a grande extensão da mesma.

\section{7 - Outras localidades}

a) Em um reconhecimento preliminar, localizamos extensa várzea turfosa de boa qualidade na margem direita do Rio Quilombo, Município de Sete Barras; também uma no Rio Ipiranga e outra no curso do Ribeirão Fundo.

A espessura verificada da turfa do Rio Quilombo, em alguns pontos, é de
$2 \mathrm{~m}$, estando a mesma sotoposta a uma camada de argila cinzenta, pouco arenosa.

b) Na várzea do Rio Pariqüera-Açu, no trecho de $10 \mathrm{~km}$, entre Pariqüera-Açu e Morro Comprido, foram encontradas também turfeiras com turfa de boa qualidade. De fácil acesso e com possibilidades em futuro próximo, do encontro de novos depósitos de turfa, sugerimos pesquisas na vasta região do Rio Una, Município de Iguape.

\section{CONCLUSÃO PRELIMINAR}

As sondagens pioneiras realizadas pelo Instituto, em área de várzea de $6.640 .000 \mathrm{~m}^{2}$, acusaram reservas de $20.904 .000 \mathrm{~m}^{3}$ de turfa úmida e... $3.600 .000 \mathrm{~m}^{3}$ de argila em grande parte aproveitável para indústria cerâmica. As reservas de argila, na realidade atingem maior volume, bem como a área pesquisada é maior, entretanto isso não é aqui exposto por escapar à finalidade do trabalho.

\section{PROPOSIÇÃO}

Sugerimos prosseguimento das pesquisas, com análise do resíduo mineral da turfa e do mangrovito, com relação aos teores em potássio e estudos detalhados da "terra füller" proveniente da decomposicão de numerosos diques de eruptiva básica existentes nas rodovias e ferrovias da região.

\section{AGRADECIMENTOS}

Agradecemos ao Dr. Sérgio Mezzalira, ex-Diretor Geral do Instituto Geológico, o interesse demonstrado em divulgar nossas pesquisas e também pelas sugestões apresentadas no desenvolvimento do texto. A Percy Corrêa Vieira, Diretor Geral do I.G. pela compreensão em dar continuidade à divulgação deste trabalho. 


\begin{tabular}{|c|c|c|c|c|c|c|}
\hline LOCALIDADE & $\begin{array}{l}\text { ÁREA DE VÁRZEA } \\
\text { PESQUISADA - } \mathrm{m}^{2}\end{array}$ & $\begin{array}{l}\text { ESPESSURA } \\
\text { MÉDIA DA } \\
\text { TURFA - m }\end{array}$ & $\begin{array}{c}\text { ESPESSURA } \\
\text { MEDIA DA } \\
\text { ARGILA - } \mathrm{m}\end{array}$ & $\begin{array}{c}\text { RESERVA DE } \\
\text { TURFA UMIDA } \\
\mathrm{m}^{3}\end{array}$ & $\begin{array}{c}\text { N. }{ }^{\circ} \text { DE SON- } \\
\text { DAGENS }\end{array}$ & $\begin{array}{l}\text { RESERVA DA } \\
\text { ARGILA - } \mathrm{m}^{3}\end{array}$ \\
\hline Rio Bamburral & 3.000 .000 & 2,00 & - & 6.000 .000 & 26 & - \\
\hline Rio Palmeiras & 280.000 & - & 2,00 & - & 21 & 560.000 \\
\hline $\begin{array}{l}\text { Rib. Vermelho } \\
\text { (cursos inf. e } \\
\text { médio) }\end{array}$ & 600.000 & 2,2 & 1,20 & 3.320 .000 & & 720.000 \\
\hline $\begin{array}{l}\text { Rib. Vermelho } \\
\text { (curso superior) }\end{array}$ & 400.000 & - & 2,00 & - & 29 & 800.000 \\
\hline Rib. Registro & 1.200 .000 & 3,00 & - & 3.600 .00 & 26 & - \\
\hline $\begin{array}{l}\text { Rib. Carapiranga } \\
\text { (curso inf., perto } \\
\text { da barra) }\end{array}$ & 300.000 & 3,20 & - & 9.600 .000 & 5 & \\
\hline $\begin{array}{l}\text { Rib. Carapiranga } \\
\text { (curso médio) }\end{array}$ & 300.000 & - & 2,0 & - & 12 & 600.000 \\
\hline Rib. Boa Vista & 400.000 & 0,80 & 1,50 & 320.000 & 24 & 600.000 \\
\hline \multirow[t]{2}{*}{ Dique Polder } & 160.000 & 0,40 & 2,00 & 64.000 & 14 & 320.000 \\
\hline & 6.640 .000 & - & - & 22.904 .000 & & 3.600 .000 \\
\hline
\end{tabular}


ESCALA HORIZONTAL 1:10000 ESCALA VERTICAL

NNE

SSO

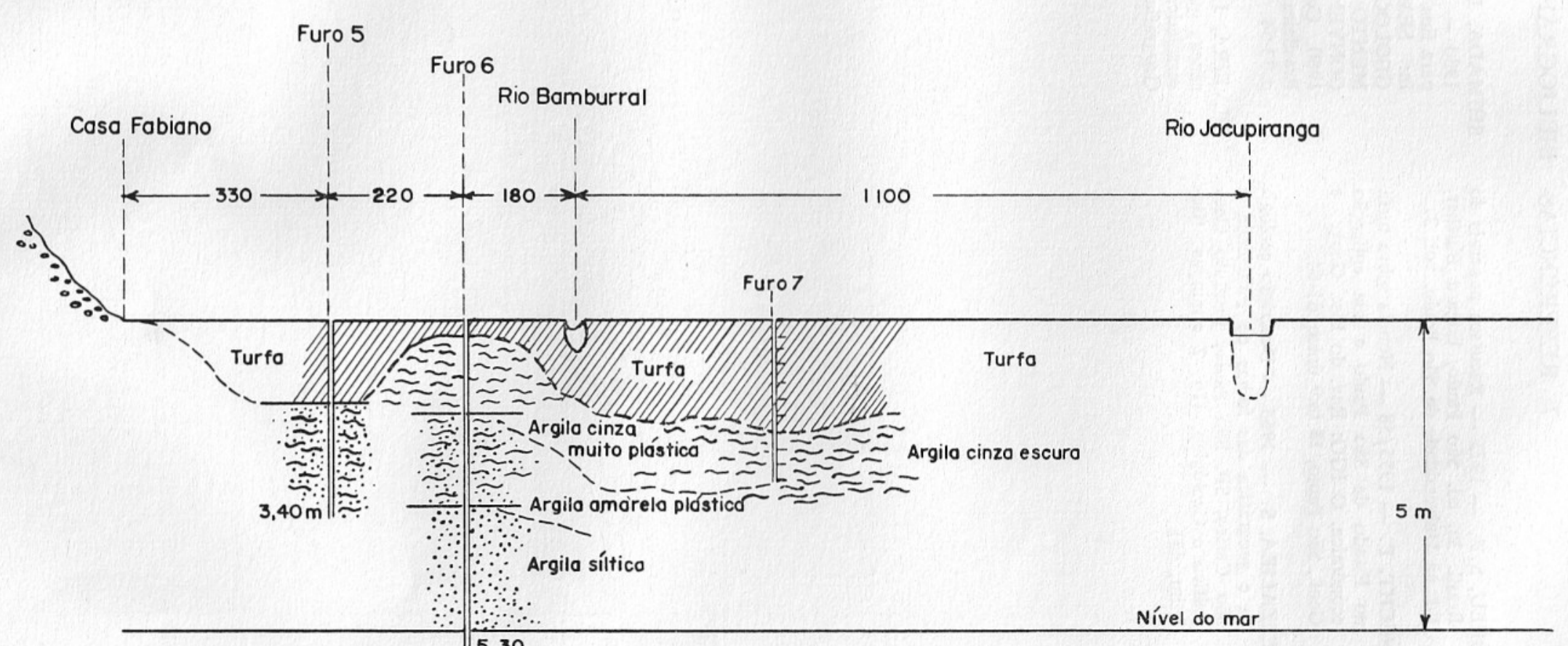




\section{REFERÊNCIAS BIBLIOGRÁFICAS}

ABREU, S.F. - 1973 - Recursos minerais do Brasil. 3a. ed. São Paulo, Edgard Blücher, Ed. na Universidade de São Paulo. vol. 2.

KNECHT, T . - 1955/58 - Notícia sobre turfa no Estado de São Paulo e sua aplicação econômica. O IGG: Rev. do Inst. Geogr. e Geol., São Paulo, 13 (n. ${ }^{\circ}$ único):61-64.

MEZZALIRA, S. - 1965 - Descrição geológica e geográfica das folhas de Piracicaba e São Carlos, SP. São Paulo, Instituto Geográfico e Geológico. 41p. 2 estampas. (Boletim, 43)
SHIMADA, H. \& CARVALHO, W.S. de 1980 - Perspectivas de utilização da turfa para fins energéticos no Estado de São Pauio. In: SEMINÁRIO CONTRIBUIÇÃO DA GEOLOGIA À BUSCA E APROVEITAMENTO DE FONTES ENERGÉTICAS CONVENCIONAIS OU NÃO, São Paulo, 1980. Comunicações. São Paulo, Sociedade Brasileira de Geologia. Núcleo de São Paulo. p. 33-64.

SILVEIRA, J.D. da - 1952 - Baixadas litorâneas quentes e úmidas. São Paulo, Universidade, FFCL. 224p. (Boletim, 152 Geografia, 8) 


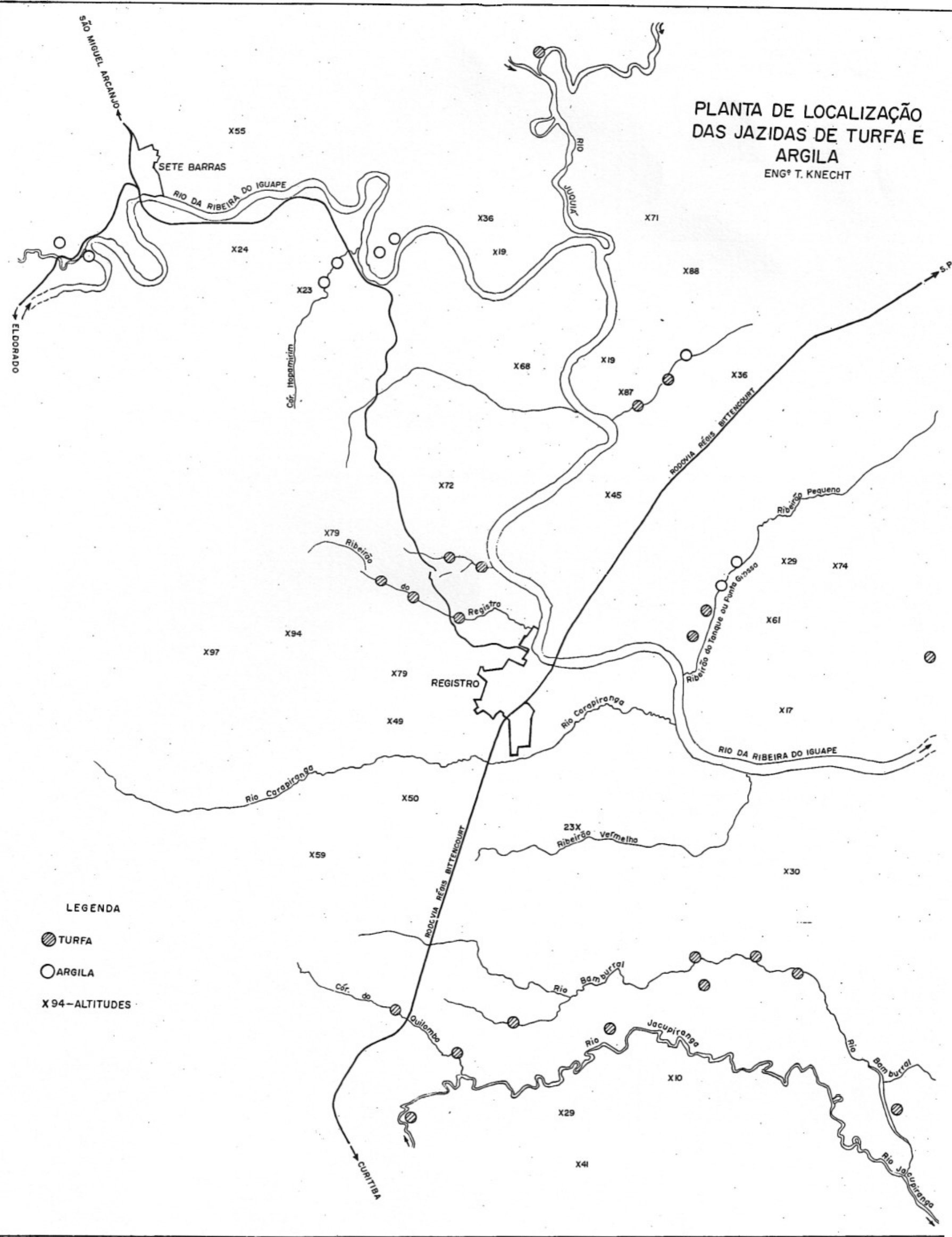

